\title{
String Vibrato: Research Related to Performance and Perception
}

By: John M. Geringer, Michael L. Alenn, $\underline{\text { Rebecca B. Macleod }}$

Geringer, J. M., Allen, M. L., \& MacLeod, R. B. (2010). String vibrato: Research related to performance and perception. String Research Journal, 1, 7-23. Copyright (C2010 American String Teachers Association. DOI: 10.1177/194849921000100101

Made available courtesy of SAGE Publications: https://doi.org/10.1177/194849921000100101

\section{(c) (1) $\Theta$ C. Attribution-NonCommercial-NoDerivatives 4.0 International License.}

\begin{abstract}
:
This article presents a summary of our presentation that was invited by the Research Committee of ASTA and given at the 2009 ASTA National Conference in Atlanta. In this article we describe and discuss previous and current research studies concerning string vibrato performance and listeners' perception of vibrato. Topics addressing performance aspects of vibrato include rates and widths, pitch center, initial direction, and continuity during slurs. Investigations that have used various approaches to determine the perceived pitch center of string vibrato are also summarized. We present suggestions for further investigation of vibrato in both the study of listener perception and performance practice and discuss pedagogical applications of research findings.
\end{abstract}

Keywords: vibrato | string instruments | pitch performance | pitch perception | string pedagogy

\section{Article}

\section{Introduction}

First, we would like to thank the Research Committee of ASTA and in particular Professor Donald Hamann for the honor of being invited to speak with you today. We take pleasure in being asked to share what we have learned about research in this area. Second, as we present the results of research that others have done, and that we have done, please keep in mind the following. There are usually several predictable reactions to summaries of research, including the question: Why would you want to study that? Conceivably the topic is viewed as dull, arcane, or outrageously wasteful in time and money (or all of the above!) and represents the outlook popularized by Senator Proxmire in the 1970s and 80s, who became known for his "Golden Fleece" Awards. After the actual results are reported, other responses may be forthcoming: 1) Well of course, that's just common sense, I've always known that, or anyone who has been a teacher knows that; or 2) No, that can't be right, that's not what my experience has been, or how can you even say that? All of these reactions are normal, understandable, and we've all had them. 
The point is that we want to engage you in some thought about an important aspect of string playing and teaching, and if we are able to get you to think about some things that might not have occurred to you previously, or to think about them even a little differently, then we will have succeeded.

A research-based approach to any subject matter stresses the importance of extended and long-term investigation as opposed to one-shot studies. What we report here is not so much a comprehensive review of literature (although we believe we included many of the most relevant studies), but an attempt to illustrate a continuing research effort intended to be applicable to some extent in both experimental and applied settings.

Among the most important aspects of string performance include the development of a beautiful tone, playing in-tune, and playing expressively. One essential facet of all three of those attributes is the vibrato. Since individual components of vibrato are neither easily perceived by the ear nor easily seen, it is difficult to know exactly how the composite sound and motions are produced. A description of the process may be troublesome to many who attempt to teach vibrato techniques, perhaps even for those who perform with a beautiful vibrato. Consequently, much of our work in trying to understand vibrato has been developing ways to visually and aurally observe what is happening during vibrato performance. This has included analysis of slow-motion video and audio excerpts of vibrato performances, analysis of vibrato waveforms, and spectral analysis of artistic performances. All of these analyses were illustrated during our presentation, unfortunately only some of these can be shown in this paper.

Vibrato has a relatively long history in the research literature regarding performance practice. Early research at the University of Iowa in the 1930s coordinated by Carl Seashore produced a number of vibrato studies that were accomplished with a phono-photograph apparatus using a stroboscopic technique for recording frequency. Seashore (1938) defined vibrato as a periodic pulsation of pitch, loudness, or timbre, singly or in combination; in quantitative terms of these factors, any particular vibrato may be discussed adequately. As an illustration of this, Figure 1 shows a college student performing a violin E4 begun with a straight tone that is then "warmed" to a vibrato. Shown are both frequency and amplitude (what we perceive as pitch and loudness) as they change over time. With audio analysis tools such as Praat (Boersma \& Weenink, 2009), we are able to determine vibrato rates and widths, pitch levels, relative intensities, and a number of other performance elements. 


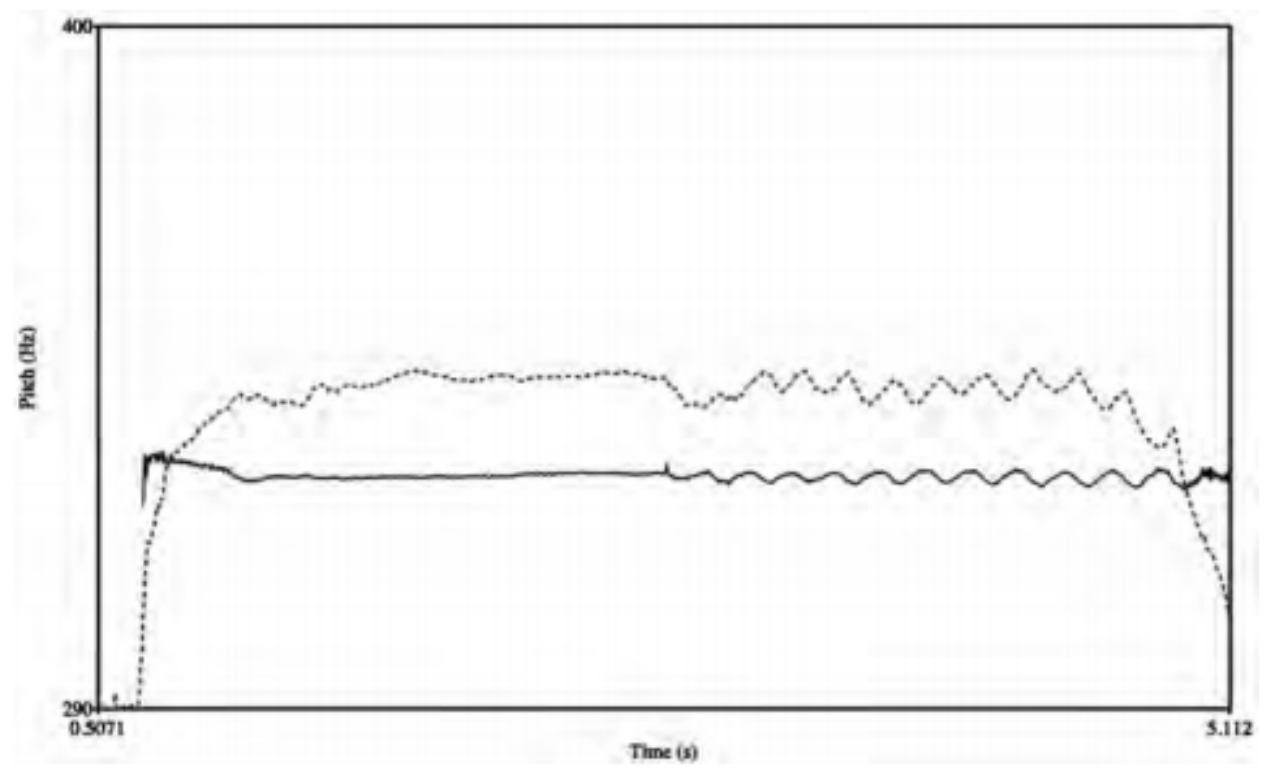

Figure 1. College student violinist playing E4: Solid line (frequency) shows that nonvibrated portion is virtually identical in frequency $(329.2 \mathrm{~Hz})$ to vibrated portion $(329.1 \mathrm{~Hz})$. Lighter dotted line shows variations in intensity during tone, especially during vibrated portion. Rate of vibrato is $5.5 \mathrm{~Hz}$; width is 24 cents.

\section{Research on Vibrato Rates}

Analysis of phonograph recordings of virtuoso string performers (Reger, 1932; Hollinshead, 1932) found rates ranging from 5.6 to $7 \mathrm{~Hz}$ (see Table 1), with Kreisler among those with the fastest rate. This research concluded that although the extent of the violin vibrato is smaller than for singing, the rates are similar. Cheslock (1931) and Small (1937) analyzed phonograph recordings of performances by Kreisler, Menuhin, Szigeti and others. Vibrato was present in almost all tones, and the mean rate was around 6.3 Hz. Results from the Iowa studies have been largely confirmed in later studies, for example, Fletcher and Sanders (1967) found vibrato rates about $6 \mathrm{~Hz}$, only slightly slower than some of the early reports. Thibeault (1997) studied solo bassists and found rates ranging from 5 to $7 \mathrm{~Hz}$ and reported a correlation of vibrato rate with tempo of excerpts, but not with pitch register. More recently, however, Geringer and Allen (2004) studied vibrato characteristics of 40 high school and college violinists and cellists. We analyzed whole notes performed in first position, and we found somewhat slower rates of vibrato, $5.5 \mathrm{~Hz}$. This finding led us to speculate that various musical factors appear to influence vibrato rates, including tempo and duration, dynamics, pitch register, style, and so on. Subsequently, MacLeod (2008, 2010) and Allen, Geringer, \& MacLeod (2009) studied the possible effects of dynamics and pitch register on vibrato rates of university and high school violin and viola players, as well as contemporary artist performers. MacLeod (2008) found that pitch height affected the vibrato rate of college and high school violin and viola players, but dynamics did not. As the instrumentalists in her 2008 study performed in a higher register, the rate of the vibrato increased slightly $(.32 \mathrm{~Hz})$. Differences in vibrato were also found between violinists and violists. Viola players' vibrato rates tended to be slower than rates of the violin players. 
Table 1. Vibrato Rates

\begin{tabular}{|c|c|c|c|c|}
\hline \\
\hline Researchers(s) & Year & Instrument & Rate $(\mathrm{Hz})$ & Level \\
\hline Cheslock & 1931 & Violin & $6.4,6.5$ & Adult, Prof. Soloists \\
\hline Hollinshead & 1932 & Violin & 7.0 & Professional Soloists \\
\hline Reger & 1932 & Violin & 6.9 & Professional Soloists \\
\hline Small & 1937 & Violin & 6.3 & Professional Soloists \\
\hline Seashore & 1938 & Violin & 6.0 & Professional Soloists \\
\hline Fletcher \& Sanders & 1967 & Violin & 6.0 & College Concertmaster \\
\hline Thibeault & 1997 & Bass & $5-7$ & Professional Soloists \\
\hline Mellody \& Wakefield & 2000 & Violin & 5.9 & Professional/Faculty \\
\hline Geringer \& Allen & 2004 & Violin/Cello & 5.5 & High School/College \\
\hline MacLeod & 2008 & Violin & 5.7 & High School/College \\
\hline MacLeod & 2008 & Viola & 5.4 & High School/College \\
\hline Allen, Geringer \& MacLeod & 2009 & Violin & $5.5,6.3$ & Artist/Faculty \\
\hline MacLeod & 2010 & Violin & 6.6 & Professional Soloists \\
\hline \multicolumn{5}{|l|}{ Specific Artists } \\
\hline Cheslock & 1931 & Violin & & \\
\hline Elman & & Violin & 6.4 & \\
\hline Heifetz & & Violin & 6.7 & \\
\hline Kreisler & & Violin & 6.2 & \\
\hline MacLeod & 2010 & Violin & & \\
\hline Bell & & Violin & 6.2 & \\
\hline Perlman & & Violin & 6.5 & \\
\hline Mutter & & Violin & 6.7 & \\
\hline Midori & & Violin & 7.1 & \\
\hline
\end{tabular}

Allen et al. (2009) completed a case study on an artist level violinist whose credits 
include positions as concertmaster of the New York Philharmonic and other major orchestras. The rate of the artist's vibrato increased in fifth position compared to first position. The mean vibrato was $5.7 \mathrm{~Hz}$ in first position and $6.3 \mathrm{~Hz}$ in fifth position. Increases in vibrato rate in the higher register averaged about . $5 \mathrm{~Hz}$ compared to that of the university and high school students' mean increases of . $32 \mathrm{~Hz}$ (MacLeod, 2008).

MacLeod (2010) investigated the influence of pitch register and dynamic level on vibrato rate of four contemporary solo artists: Joshua Bell, Anne-Sophie Mutter, Itzhak Perlman, and Midori. Overall mean vibrato rate of the performers was $6.63 \mathrm{~Hz}$. A moderate correlation $(\mathrm{r}=$ .44) was found between the dynamic level of a tone and the rate of vibrato for the four artists combined. However, further analysis revealed that the degree of association varied considerably between individual performers. There was no correlation between pitch register and rate for these artist level performers.

\section{Research on Vibrato Width}

Researchers at the University of Iowa in the 1930s also investigated vibrato width. Table 2 summarizes much of this early research as well as more recent work. Reger (1932), for example, showed that widths varied with the experience level of the performers. The students he studied had average vibrato widths of about 38 cents, widths of teachers were about 42 cents, and those of professional soloists were 48 cents, about one-quarter tone. The violin examples in the McGill University Master Samples database (Mellody \& Wakefield, 2000) and the high school and college students of Geringer and Allen (2004) had somewhat narrower widths, about 30 cents. We noted that violinists' mean vibrato widths were about 8 cents wider than those of cellists, and we found slight differences in experience levels. Again, findings suggested that musical contexts contributed greatly to the performers' widths. Subsequent research by Allen et al. (2009), and MacLeod $(2008,2010)$, has contributed to further understanding of these contextual factors.

MacLeod (2008) found that vibrato width of high school and university violin and viola players was influenced by both pitch register and dynamic level. Performers vibrated 26 cents wider during high tones than during low tones in her study. Consistent with these findings, Allen et al. (2009) found that the former concertmaster of the New York Philharmonic had widths of 40 cents in first position and up to 108 cents in fifth position. Furthermore, MacLeod (2010) investigated the influence of pitch height on width and found that Bell, Mutter, and Midori tended to increase vibrato extents in the upper register. However, Perlman's vibrato was not consistently wider in the upper range. Notes with a frequency above A5 $(880 \mathrm{~Hz})$ generally were performed with wider vibrato ( $M=67.9$ cents) than notes in the lower register $(M=54.7$ cents). The minimum cent deviation produced by these artists during vibrato was 24 cents (about 1/8 tone) and the maximum was 129 cents, more than a semitone. Although a trend for larger widths in higher registers was found, it should be noted that dynamics, expression, tempo, "warming", and other contextual factors produced much variability in performances of each artist. Further research is necessary to understand and define specific effects of such factors on vibrato widths.

Dynamic levels also influenced vibrato widths of high school, university, and artist level upper strings players (MacLeod, 2008, 2010). University and high school violinists and violists increased vibrato width approximately 4 cents in the forte passages compared to the piano passages. Furthermore, violinists demonstrated a tendency to vibrate wider than violists, and university performers varied their vibrato width to a greater extent between the piano and forte 
passages than did high school performers. Moderate positive correlations were found also for dynamic level and vibrato width $(\mathrm{r}=.49)$ in artist level performers. The degree to which vibrato width changed with dynamic level varied from performer to performer (Perlman, $\mathrm{r}=.63$; Bell $\mathrm{r}=$ .58 ; Mutter $\mathrm{r}=.38$; Midori $\mathrm{r}=.63$ ).

Table 2. Vibrato Widths

\begin{tabular}{|c|c|c|c|c|}
\hline \\
\hline Researcher(s) & Year & Instrument & Rate $(\mathrm{Hz})$ & Level \\
\hline Hollinshead & 1932 & Violin & 52 & Professional \\
\hline Reger & 1932 & Violin & 48 & Professional Soloists \\
\hline Reger & 1932 & Violin & 38 & Students \\
\hline Reger & 1932 & Violin & 42 & Teachers \\
\hline Small & 1937 & Violin & 44 & Professional Soloists \\
\hline Mellody \& Wakefield & 2000 & Violin & 30 & Professional/Faculty \\
\hline Geringer \& Allen & 2004 & Violin/Cello & 30 & High School/College \\
\hline MacLeod & 2008 & Violin & 46.5 & High School/College \\
\hline MacLeod & 2008 & Viola & 37.5 & High School/College \\
\hline Allen, Geringer, \& MacLeod & 2009 & Violin & $40-108$ & Artist/Faculty \\
\hline MacLeod & 2010 & Violinists & 63 & Professional Solos \\
\hline \multicolumn{5}{|l|}{ Specific Artists } \\
\hline MacLeod & 2010 & Violin & & \\
\hline Bell & & Violin & $61(28-100)$ & \\
\hline Perlman & & Violin & $63(26-129)$ & \\
\hline Mutter & & Violin & $68(24-90)$ & \\
\hline Midori & & Violin & $60(40-88)$ & \\
\hline
\end{tabular}

These findings are mostly consistent with previous research by Reger (1932) where more experienced performers and soloists performed with a faster and wider vibrato than did the students. Based on the results of current research (Allen et al., 2009; Geringer \& Allen, 2004; Geringer, et al., 2005; MacLeod, 2008, 2010), it is apparent that artist level performers vibrate both faster and wider than student performers. However, a qualification should be added: Most of the analyses of artist-level players were based on material within a music performance context, that is, passages had faster tempi, larger range in pitch registers, and wider dynamic 
ranges than material written for the younger performers. These factors in addition to experience all appear to influence performed vibrato rates and widths.

\section{Research on Vibrato Pitch Center Performance}

A number of early studies provided evidence for Seashore's view (1938) that vibrato oscillations extend both above and below conceived pitch. He and his colleagues concluded that the mean pitch of the vibrato cycle corresponds to the conceived pitch (with the exception of leading tones). Table 3 shows that most research has corroborated this idea. Shackford (1960), for example, studied violinists of the Boston Symphony by comparing intonation of performed open A4, stopped (non-vibrated) A4, and vibrated A4. Measurement of oscillations of the vibrated tones showed that the extent of vibrato was equal both above and below pitches performed without vibrato.

\begin{tabular}{|c|c|c|c|}
\hline Center & Researcher & Year & Reference Point \\
\hline \multicolumn{4}{|l|}{ Above: } \\
\hline & Fletcher, Blackham \& Geersten & 1965 & equal temperament \\
\hline & Papich \& Rainbow & 1974,1975 & equal/Pythagorean \\
\hline \multicolumn{4}{|l|}{ Below: } \\
\hline & Fletcher \& Sanders & 1967 & equal temperament \\
\hline \multicolumn{4}{|c|}{ Around (Above and Below) } \\
\hline & Small & 1937 & equal temperament \\
\hline & Seashore & 1938 & $\begin{array}{l}\text { summary of series of } \\
\text { studies }\end{array}$ \\
\hline & Shackford & 1960 & $\begin{array}{l}\text { reference tone and } \\
\text { individuals' pitch } \\
\text { center }\end{array}$ \\
\hline & Brown \& Vaughn & 1996 & listener perception \\
\hline & Mellody \& Wakefield & 2000 & equal temperament \\
\hline & Geringer \& Allen & 2004 & $\begin{array}{l}\text { individuals' pitch } \\
\text { center }\end{array}$ \\
\hline & Geringer, Allen, \& MacLeod & 2005 & $\begin{array}{l}\text { individuals' pitch } \\
\text { center }\end{array}$ \\
\hline
\end{tabular}




\begin{tabular}{|l|l|l|l|}
\hline & Allen, Geringer, \& MacLeod & 2009 & artist's pitch center \\
\hline & Geringer, MacLeod, \& Allen & 2010 & $\begin{array}{l}\text { perception: listeners } \\
\text { matched vibrato tones } \\
\text { with non-vibrato tones }\end{array}$ \\
\hline
\end{tabular}

We have found only 3 sets of research studies that indicate contrary findings. Fletcher, Blackham, and Geertsen (1965) observed vibrato performances of one student on each string instrument. They found that the lower extent of vibrated tones of violin, viola, cello, and bass students approximated the target pitch frequency and that vibrato fluctuated above that pitch. Close inspection of the graphs included in the article show that the initial (sharp) tuning of the instruments might have influenced this outcome. Papich and Rainbow $(1974,1975)$ measured vibrato of four performers of each string instrument and observed that the lower part of the vibrato modulations tended to coincide primarily with pitches associated with either Pythagorean or equal tempered tuning. They noted that pitch errors in ensemble performance appeared to be sharp; this tendency can be seen in the figure shown in the 1974 article. A second investigation by Fletcher (Fletcher \& Sanders, 1967) was a continuation of the Fletcher et al. (1965) work and found results directly contrary to the initial study. Most of the violin tones performed by the concertmaster of a university orchestra oscillated from the intended pitch (based on an equal tempered A-440 standard) and below; however as in the first study, description of the tuning procedure used prior to recording was not clear, which may help account for the differing outcomes.

Most recently, our research with high school and university students (Geringer \& Allen, 2004; Geringer, et al., 2005) and an artist-level case study (Allen, et al., 2009) has shown consistent support for the finding that vibrato is an oscillation both above and below the performer's conceived pitch. In the 2004 study, we determined each individual's intended center of pitch with 40 high school and college violin and cello students by asking them to play stopped tones without vibrato followed by the same tone with vibrato. Means were found to be virtually identical; performers vibrated both above and below the conceived pitch (as determined by their non-vibrated tones) rather than chiefly above or below the conceived pitch. There was little asymmetry in either direction of the oscillations from the mean. In the 2005 study we asked another set of 40 high school and college cello and violin performers to "warm" a series of notes, that is, to initiate tone without vibrato for the first two beats of a whole note and then to begin vibrating on beat 3 for the duration of the note. If players vibrated mostly upward or mostly downward from the pitch center, the means of vibrated notes would have been correspondingly higher or lower than means of non-vibrated notes. Again we found that mean pitch levels of these performers were not significantly different when using vibrato versus no vibrato on the same note. An extended analysis (Allen, et al., 2009) of an artist-level performer showed that vibrato was equally above and below intended pitch in first position. In the fifth position, this observation was also chiefly accurate, however, there was a very slight tendency for the vibrato center to be slightly sharper (about 5 cents) than the non-vibrated center.

\section{Research on Initial Direction of Vibrato Motion}

Although there is much pedagogical material regarding the initial motion used in vibrato, there is a little research. Small (1937) and Papich and Rainbow (1974) reported that initial 
vibrato motion of more advanced players was toward the bridge (a sharpening motion). We have found no systematic investigation of this issue other than our own (Allen et al., 2009; Geringer et al., 2005). As noted in the section above, we used "warming" exercises in the attempt to determine whether performers' initial vibrato movements were consistently backward (in the direction of the scroll) or a forward motion toward the bridge. In the case study (2009), we used a slow motion video analysis to help address this question; in the study with 40 high school and college students (2005), we analyzed frequency graphs of individuals' vibrato. In the 2005 study we found no consistent patterns regarding the direction of change when initiating vibrato from non-vibrato. These student performers began vibrato cycles with a forward motion about as frequently as they began with a backward motion. We found no differences as a result of experience level, between cellists and violinists, fingers, or any combination of factors. We did find it difficult in a number of cases to judge exactly when the performer initiated vibrato and therefore to determine the initial direction. There was often a lack of pitch stability prior to obvious vibrato cycles. Slow motion video analysis of the artist-level performer demonstrated that generally, the frequency initially became very slightly unstable and the first relatively large frequency change occurred generally in a downward direction (in the direction of the scroll). Video showed that the performer's left hand was repositioned in preparation for the vibrato motion; the first finger knuckle was moved a greater distance away from the side of the violin neck. As with the younger performers, it was difficult to pinpoint the exact time of vibrato initiation (see Figure 2). Perhaps our "warming" task may have created an artificial situation and thus contributed to some hesitancy on the part of the performers in beginning their vibrato.

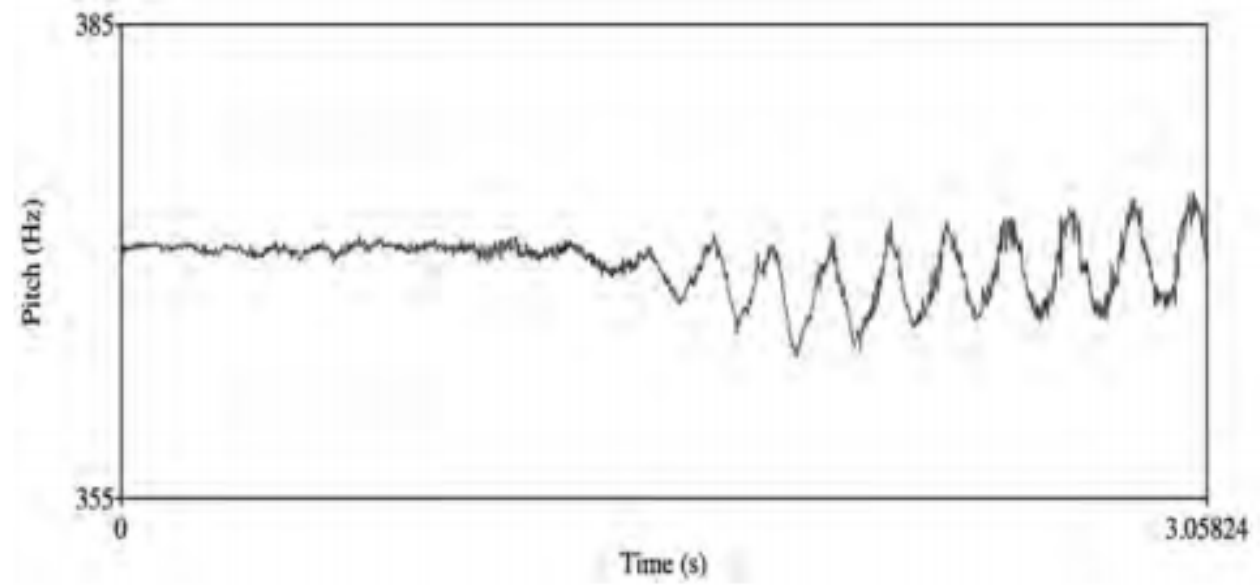

Figure 2. An artist-level violinist playing $\mathrm{F}_{4}$ with no vibrato warming to vibrato. Note the instable frequency in preparation for the vibrato motion. Mean frequency of both portions is approximately $370.5 \mathrm{~Hz}$. Rate of vibrato is $5.7 \mathrm{~Hz}$; width is 38 cents.

\section{Continuity of Vibrato}

Little research literature exists regarding vibrato continuity, although as with initial movement, a number of pedagogues have recommended various exercises and routines to develop a continuous vibrato. In our second study of high school and college cello and violin players (Geringer et al., 2005), we investigated the continuity of vibrato during the transition between slurred notes. All performers stopped vibrating during at least some portion of the 
transition. The mean duration of the non-vibrato portion of university students was 0.42 second, and 0.50 second (one-half second) for the high school students. Most players stopped vibrating about .20 to .25 of a second prior to the change to the new note, in preparation for the finger change. Then, as the new note began, there was another brief period of non-vibration (about 0.20 second), before the regular pattern of vibrato was apparent. The artist-level performer (Allen et al., 2009) also stopped vibrating, though for a shorter period, during the transition between slurred notes. The mean duration of non-vibrato portions was .33 second. It was clear in graphic displays of this performer's performances that almost all of the non-vibrating portions occurred during preparation for the change to the subsequent note; the new note was begun with full vibrato virtually immediately. When listening carefully to the artist's slurs, we often were unable to hear the non-vibrating portions (even though we knew they were there!), as opposed to when we listened to the younger players the non-vibrating segments were usually perceptible. Additional research with various experience levels would help clarify whether the lengthier non-vibrato portion of less experienced performers results chiefly from a delay of vibrato initiation on the new note.

\section{Listeners' Perception of Pitch Center during Vibrato}

A number of empirical studies have investigated the pitch that listeners perceive in frequency-modulated sounds such as vibrato. Because of the necessity of stimulus control in experimental studies of perception, most all previous research has used electronic or synthesized sound sources in place of acoustical instruments. Most of these studies show that perceived pitch corresponds closely to the mean of the frequency-modulated sound (Iwamiya, Kosugi, \& Kitamura, 1983; Seashore, 1938; Shonle \& Horan, 1980). Shonle and Horan found that perceived pitch of wider (whole-tone) modulations corresponded more closely to the geometric mean of the extreme frequencies, a frequency only slightly lower than the arithmetic mean. Brown's (1991) musician listeners located pitch of vibrato slightly higher in frequency than did non-musicians.

We found only one earlier study that used an unaltered acoustic string instrument for stimulus presentations. Brown and Vaughn (1996) recorded a professional violist performing with and without vibrato. The 11 listeners included six amateur musicians, four graduate violin students and one professional violinist. Auditors heard paired comparisons wherein a vibrato tone was followed by a non-vibrato tone that was either higher or lower in frequency than the vibrato tone. Although sample size was limited, results were consistent with most of the above empirical studies: judged pitch of vibrato tones corresponded to the arithmetic mean of the vibrato.

Recently we investigated the location of perceived pitch in string vibrato tones among 72 music majors (Geringer, MacLeod, \& Allen, 2010). We used recordings of acoustic instruments (cello and violin) to provide both vibrato stimulus tones and the non-vibrato tones that listeners adjusted. Vibrato tone stimuli were presented in one speaker, and the non-vibrato tones in the other speaker. Listeners turned a CRDI (Continuous Response Digital Interface) dial to raise or lower the frequency of the non-vibrating violin or cello tone until they were able to match the pitch that they heard in the vibrato tone. We were interested also in whether there were differences in perceived pitch of vibrato tones between string performers and non-string music majors and between cello and violin stimuli. We found that both groups of music major listeners perceived the pitch of vibrato tones very near the center of the vibrato for cello and violin tones, 
not the high or low points of the vibrato extents. Mean vibrato pitch perception of those with string performance experience was no different than music majors without string experience; however, there was a difference between these groups in the spread of scores. String players exhibited significantly less variation in tuning judgments than non-string players. Our results concerning the pitch heard in vibrato were consistent with earlier studies using electronic stimuli (Iwamiya, Kosugi, \& Kitamura, 1983; Shonle \& Horan, 1980; Seashore, 1938), as well as acoustic material (Brown \& Vaughn, 1996). These results provide additional evidence that listeners apparently perceive the pitch intended by the performer, that is, the mean of the performed vibrato extents.

\section{Summary and Discussion}

Descriptive research is designed to do just that, to describe what occurred in a particular set of circumstances. It cannot, nor is it intended to tell teachers or students the correct way to do something; for example, nothing in the reported research on rates and widths suggests that there is a "best" rate or "ideal" rate or width for all contexts. Results of research do provide information however, that might be utilized in teaching by providing possible alternatives for various situations and musical contexts. As an example, if we determine that a virtuoso performer such as Perlman or Midori vibrates at rates between 6.5 and $7 \mathrm{~Hz}$, does that mean that we should teach our students to do the same? The decision itself has nothing to do with research. The decision can only be informed by research, for example, are those rates characteristic of orchestral performers or only world-class solo artists? Some might suggest that if one were to vibrate with rates that fast at an orchestral audition, the job would be given to someone with a rate similar to the other section players, perhaps between 5 and $6 \mathrm{~Hz}$.

Pedagogues have generally suggested rates should be in the range from 5 to $7 \mathrm{~Hz}$ (e. g., Applebaum, 1986; Fischbach, 1998; Rolland, 2000). Some advocate that the performer should control rates to create variety or expression (Applebaum, 1986; Galamian, 1962), while others suggest that rate should be constant and only width should vary (Joelson, 1964). Empirical studies from the 1930s to the present have observed that rates usually fall within this same range of 5-7 Hz. We have noted that 1) rates tend to be slightly higher with increased levels of expertise; and 2) vibrato rates tend to be higher with increased pitch levels. Further research should be undertaken to broaden our understanding concerning effects of dynamics, tempo, styles, and other contextual variables (such as solo vs. ensemble performance) on rates.

Pedagogical discussion of widths seems to be in general agreement that vibrato should approximate a quarter-tone (50 cents) in width (Fischbach, 1998; Lucktenberg, 1994; Rolland, 2000). Fischbach differentiated between width of soloists (approaching a half-step) and widths of ensemble performers (about a quarter-tone). Doscheck (1968) reported typical widths as between 25 and 35 cents with extremes from 10 to 60 cents. The research literature has shown that in general, training and level of expertise influences width: Professional artists use a wider average vibrato $(50-60$ cents) than do ensemble and student performers $(20-45$ cents). Pitch register (wider vibratos are generally used in higher positions) and dynamic levels (wider vibratos are found with increased dynamic levels) also influence width. There appears to be some differences between instruments; violinists tend to vibrate slightly wider than violists and cellists. Perhaps this may result somewhat from the differences in spatial relationships on the fingerboards of instruments as opposed to decisions relating to expressive variation. As with rates, effects of other music context variables remain to be systematically studied. 
A number of pedagogues, Galamian (1962), Fischer (1997), and Young (1999) for example, suggest that students should aspire to develop an uninterrupted vibrato. Not one of our high school or university cello or violin students demonstrated the ability to vibrate continuously from one finger to another. This was the case also with the artist-level performer we studied, although it should be noted that in most instances the non-vibrated portions were not aurally perceivable and were shorter than for the less advanced performers. More research is recommended with professional string performers to help establish the actual parameters and possibilities of a model vibrato. Physical constraints inherent in the vibrating components of the instrument and/or in moving between notes may preclude an absolutely continuous vibrato. It may be that advanced performers are able to only reduce the amount of non-vibrato present in changes between fingers, rather than eliminate it altogether.

Perhaps the most contentious information concerns the pitch center of vibrato and related topics that include the initial motion and how vibrato is perceived. Fischbach (1998) observed "Some string pedagogues are convinced that the vibrato ornament occurs from the perceived pitch downward, some believe vibrato happens above the original pitch, while others are adamant that the perceived pitch is in the middle of the sine wave" (p. 29). It seems logical that there would be a relationship between the recommended direction of initial movement and pitch center if vibrato occurs primarily above or below the conceived pitch. Descriptions of a backward motion (toward the pegs) are most prevalent in the pedagogical literature (e.g., Applebaum, 1986; Galamian, 1962; Hamann \& Gillespie, 2004), although others advocate for initial motion toward the bridge (e.g., Fischer, 1997, Rolland, 2000). Only a few pedagogues report that the pitch center is in the middle of the vibrato with oscillations occurring both above and below conceived pitch (Mantel, 1972; Rolland, Mutchler, \& Hellebrandt, 2000; Young, 1999). Fischbach (1998) concluded that the pitch center likely varies from performer to performer and is not consistent.

Although two early studies reported that initial vibrato motion of more advanced players appeared to be toward the bridge, in our study of high school and college cellists and violinists we found no consistent pattern either forward or backward regarding initial motion. We noted the difficulty in determining exactly the point of initiation; pitch instability was common immediately prior to onset of vibrato. With the advanced artist we studied, the first relatively large frequency change appeared generally in a backward direction (in the direction of the scroll), even though vibrato extents were clearly both above and below conceived pitch. Additional study should consider using other means of assessing initial motion in addition to the "warming task" we used.

The predominant research finding regarding the performed pitch center of vibrato is that it coincides with the intended pitch, that is, vibrato oscillates both above and below pitch. This outcome has been found consistently since the 1930s with only a few, arguable exceptions. Our analyses of 80 high school and college students and several advanced cellists and violinists showed that the mean of vibrato tones coincided with the mean of the same notes played without vibrato (either successively or in a "warming" context). In all of those analyses, we did find some examples of vibrato oscillations that were mostly from the conceived pitch and below, and a few that were mostly above. However, we found no examples that were only in one direction or the other.

One of the most critical aspects of vibrato performance concerns pitch perception, that is, whether or not the note is perceived as being "in tune". Most all perception studies, using either electronic or acoustic sound sources, have shown that listeners perceive the pitch of modulated 
tones at the center (mean) frequency of modulation. In our recent study, 72 music majors were asked to turn a dial that controlled the pitch of a non-vibrated cello or violin tone until it matched the perceived pitch of a corresponding vibrated tone. Average tuning responses for all tones were within 2 cents of the center of the vibrated tone. There was no indication that any listeners perceived either the highest or lowest part of the vibrato cycle. Suggestions of pedagogues that vibrato should oscillate around the pitch center (e.g., Fischbach \& Frost, 1997; Mantel, 1972; Young, 1999) seem to be consistent with what listeners perceive. Mantel, for example, summarized that "Thus, the tone that the listener hears is exactly in the middle between the extreme pitches of the vibrato" (p. 108).

Obviously string players have learned how to vibrate for many generations without having access to research results, and will continue to do so. However, it may be that asking questions, analyzing performances, studying principles of physical motion and acoustics of string instruments, and so on could contribute a great deal to our collective efforts. Perhaps we as teachers could become more effective and students might achieve increased and/or earlier success.

We would like to add one further cautionary note. Experimental research, however well controlled, should be viewed as only one mode of inquiry with which to pursue improving our teaching and becoming more effective pedagogues. It is inadvisable that any one study or one mode of inquiry be accepted as the final arbiter of truth. Continuing cycles of analysis and synthesis should provide support or refutation for relevant aspects of individual studies. With these and all other due cautions, we hope that information gained from this and any other systematic line of research studies will find application by music teachers to provide successful and rewarding musical experiences.

\section{References}

Allen, M. L., Geringer, J. M., \& MacLeod, R. B. (2009). Performance practice of violin vibrato: An artist-level case study. Journal of String Research, 4, 27-38.

Applebaum, S. (1986). Vibrato. In The art and science of string performance (pp. 64-71). Van Nuys, CA: Alfred.

Boersma, P., \& Weenink, D. (2009). Praat: doing phonetics by computer (Version 5.1.06) [Computer program]. Retrieved May 11, 2009, from http://www.praat.org/

Brown, J. C., \& Vaughn, K. V. (1996). Pitch center of stringed instrument vibrato tones. Journal of the Acoustical Society of America, 100, 1728-1735.

Brown, S. F. (1991). Determination of location of pitch within a musical vibrato. Bulletin of the Council for Research in Music Education, 108, 15-30.

Cheslock, L. (1931). An introductory study of the violin vibrato. Research Studies in Music, 1. Baltimore: Peabody Conservatory.

Doschek, A. (1968). Some physical aspects of the vibrato. American String Teacher, 18(3), 19-20.

Fischbach, G. (1998). The birth of a vibrato. American String Teacher, 48(4), 28-35.

Fischbach, G. F., \& Frost, R. S. (1997). Viva vibrato. San Diego, CA: Neil A. Kjos. Fischer, S. (1997). Vibrato. In Basic: 300 exercises and practice routines for the violin/viola (pp. 662-663). London: Edition Peters.

Fletcher, H. E., \& Sanders, L. C. (1967). Quality of violin vibrato tones. Journal of the Acoustical Society of America, 41, 1534-1544. 
Fletcher, H. E., Blackham, D., \& Geertsen, N. (1965). Quality of violin, viola, cello, and bass-viol tones. Journal of the Acoustical Society of America, 37, 851-863.

Galamian, I. (1962). Vibrato. In Principles of violin playing and teaching (pp. 37-43). Englewood Cliffs, NJ: Prentice-Hall.

Geringer, J. M., \& Allen, M. L. (2004). An analysis of vibrato among high school and university violin and cello students. Journal of Research in Music Education, 52, 167-178.

Geringer, J. M., Allen, M. L., \& MacLeod, R. B. (2005). Initial movement and continuity in vibrato among high school and university string players. Journal of Research in Music Education, 53, 248-259.

Geringer, J. M., MacLeod, R. B., \& Allen, M. L. (2010). Perceived pitch of violin and cello vibrato tones among music majors. Journal of Research in Music Education, 57, 351-363.

Hamann, D., \& Gillespie, R. (2004). Strategies for teaching strings: Building a successful string and orchestra program. New York: Oxford University Press.

Hollinshead, M. T. (1932). A study of the vibrato in artistic violin playing. In C. E. Seashore (Ed.), University of Iowa studies in the psychology of music: Vol. 1. The vibrato (pp. 281-288). Iowa City: University of Iowa.

Iwamiya, S., Kosugi, K., \& Kitamura, O. (1983). Perceived principal pitch of vibrato tones. Journal of the Acoustical Society of Japan (E), 4(2), 73-82.

Joelson, E. W. (1964). Teaching violin vibrato-start early. American String Teacher, 14(3), 17-20.

Lucktenberg, J. (1994). Developing violin vibrato. The Instrumentalist, 48(10), 32-36.

MacLeod, R. B. (2008). Influences of dynamic level and pitch register on the vibrato rates and widths of violin and viola players. Journal of Research in Music Education, 56, 43-54.

MacLeod, R. B. (2010). A pilot study of relationships between pitch register and dynamic level and vibrato rate and width in professional violinists. String Research Journal, I, 75-83.

Mantel, G. (1972). Cello technique: Principles of forms of movement. (B. H., Thiem, Trans.). Bloomington \& London: Indiana University Press.

Mellody, M., \& Wakefield, G. H. (2000). The time-frequency characteristics of violin vibrato: Modal distribution analysis and synthesis. Journal of the Acoustical Society of America, 107(1), 598-611.

Papich, G., \& Rainbow, E. (1974). A pilot study of performance practices of twentieth century musicians. Journal of Research in Music Education, 20, 24-34.

Papich, G., \& Rainbow, E. (1975). Research in the performance practices of musicians. Psychology of Music, 22, 4-8.

Reger, S. N. (1932). The string instrument vibrato. In C. E. Seashore (Ed.), University of Iowa studies in the psychology of music: Vol. 1. The vibrato (pp. 305-338). Iowa City: University of Iowa.

Rolland, P. (2000). Basic principles of violin playing (2nd Ed.). Mesa, AZ: Clara Roland.

Rolland, P., Mutchler, M., \& Hellebrandt, F. (2000). The teaching of action in string playing. (3rd ed.). Urbana, IL: Illinois String Research.

Seashore, C. E. (1938). A musical ornament, the vibrato. In Psychology of music (pp. 33- 52). New York: McGraw-Hill.

Shackford, C. (1960). Pitch range and the actual pitch of vibrato tones. American String Teacher, $10(2), 25,28$.

Shonle, J. I., \& Horan, K. E. (1980). The pitch of vibrato tones. Journal of the Acoustical Society of America, 67, 246-252.

Small, A. M. (1937). An objective analysis of artistic violin performance. In C. E. Seashore 
(Ed.), University of Iowa studies in the psychology of music: Vol. 4. Objective analysis of musical performance (pp. 172-231). Iowa City: University of Iowa.

Thibeault, M. (1997). The vibrato rate of professional double bass players. American String Teacher, 47(1), 71-73.

Young, P. (1999). Great shakes: Matchboxes and sponges - expert tips on teaching vibrato. Strad, 110(1313), 934-937. 